THE AFFORDABLE CARE ACT AFTER A DECADE: INDUSTRIAL ORGANIZATION OF THE INSURANCE EXCHANGES

\author{
Benjamin R. Handel \\ Jonathan T. Kolstad \\ Working Paper 29178 \\ http://www.nber.org/papers/w29178 \\ NATIONAL BUREAU OF ECONOMIC RESEARCH \\ 1050 Massachusetts Avenue \\ Cambridge, MA 02138 \\ August 2021
}

This paper was produced as an invited manuscript for the Annual Review of Economics, Volume 14, to be published in 2022 with DOI https://doi.org/10.1146/annurev-economics051420-114714. We thank Sofya Shchukina for valuable research assistance. The views expressed herein are those of the authors and do not necessarily reflect the views of the National Bureau of Economic Research.

NBER working papers are circulated for discussion and comment purposes. They have not been peer-reviewed or been subject to the review by the NBER Board of Directors that accompanies official NBER publications.

(C) 2021 by Benjamin R. Handel and Jonathan T. Kolstad. All rights reserved. Short sections of text, not to exceed two paragraphs, may be quoted without explicit permission provided that full credit, including $\odot$ notice, is given to the source. 
The Affordable Care Act After a Decade: Industrial Organization of the Insurance Exchanges Benjamin R. Handel and Jonathan T. Kolstad

NBER Working Paper No. 29178

August 2021

JEL No. G22,H2,I11,I13

\begin{abstract}
$\underline{\text { ABSTRACT }}$
The regulated insurance exchanges set up in the Affordable Care Act (ACA) were designed to deliver affordable, efficient health coverage through private insurers. It is crucial to study the complex industrial organization (IO) of these exchanges in order to assess their impacts to date, during the first decade of the ACA, and in order to project their impacts going forward. We revisit the inherent market failures in health care markets that necessitate key ACA exchange regulations and investigate whether they have succeeded in their goals of expanding coverage, creating robust marketplaces, providing product variety, and generating innovation in health care delivery. We discuss empirical IO research to date and also highlight shortcomings in the existing research that can be addressed moving forward. We conclude with a discussion of IO researchbased policy lessons for the ACA exchanges and, more generally, for managed competition of private insurance in health care.
\end{abstract}

Benjamin R. Handel

Department of Economics

University of California, Berkeley

508-1 Evans Hall \#3880

Berkeley, CA 94720

and NBER

handel@berkeley.edu

Jonathan T. Kolstad

Haas School of Business

University of California, Berkeley

Berkeley, CA 94720

and NBER

jkolstad@berkeley.edu 


\title{
The Affordable Care Act After a Decade: Industrial Organization of the Insurance Exchanges*
}

\author{
Ben Handel ${ }^{\dagger} \quad$ Jonathan Kolstad $\ddagger$
}

August 17, 2021

\begin{abstract}
The regulated insurance exchanges set up in the Affordable Care Act (ACA) were designed to deliver affordable, efficient health coverage through private insurers. It is crucial to study the complex industrial organization (IO) of these exchanges in order to assess their impacts to date, during the first decade of the ACA, and in order to project their impacts going forward. We revisit the inherent market failures in health care markets that necessitate key ACA exchange regulations and investigate whether they have succeeded in their goals of expanding coverage, creating robust marketplaces, providing product variety, and generating innovation in health care delivery. We discuss empirical IO research to date and also highlight shortcomings in the existing research that can be addressed moving forward. We conclude with a discussion of IO research-based policy lessons for the ACA exchanges and, more generally, for managed competition of private insurance in health care.
\end{abstract}

\section{Introduction}

The Affordable Care Act (ACA) was a generational change in health policy as well as one of the most politically divisive issues in recent U.S. history. At its heart, the ACA leverages the development of insurance markets to achieve the

\footnotetext{
*This paper was produced as an invited manuscript for the Annual Review of Economics, Volume 14, to be published in 2022 with DOI https://doi.org/10.1146/annurev-economics051420-114714

$\dagger$ UC Berkeley and NBER, handel@berkeley.edu

${ }^{\ddagger}$ UC Berkeley and NBER, jkolstad@berkeley.edu
} 
goals of expanding insurance coverage to near-universal levels and facilitating cost-reducing and quality-enhancing innovation in health care delivery. Accomplishing these twin aims depends critically on creating appropriate incentives, regulatory structures and market designs. Accordingly, industrial organization (IO) questions lie at the heart of both evaluating the ACA over its first 10 years and identifying avenues for improving upon it going forward.

In this piece we analyze and interpret some of the central research findings that relate to IO and the ACA. A comprehensive assessment of the implications of the ACA, even limiting ourselves to one corner of economics, is beyond the scope of this article. Instead, we focus our attention on a subset of issues where we believe critical questions that have captured the attention of IO economists have an important role to play in understanding the experience of the ACA to date and ways to improve upon it in the future. While the ACA is a wide-ranging, multi-faceted law, we concentrate our attention on one particular aspect: the operation of the ACA exchanges, and the non-group insurance market more generally.

The exchanges are a centerpiece of the ACA and represent a valuable case study for considering the application of IO tools to manage competition in health insurance markets. Appropriately designing and supporting competition is the central issue facing any market-based health care system, making insights from evaluating the ACA exchanges valuable beyond the ACA context itself (Arrow (1963), Enthoven (1993)). Some of the specific IO topics we emphasize include (i) facilitating price competition in insurance markets through subsidy and product regulation (ii) contending with adverse selection without exacerbating reclassification risk (iii) consumer choice frictions and market function and (iv) insurer entry and product innovation.

In order to put these IO questions in the appropriate context, we begin by asking why regulation in general, and the ACA specifically, was introduced to facilitate market function in the health insurance market. For example, was the individual mandate necessary? What role do subsidies play in market function? How effective were risk sharing policies (e.g., risk adjustment)? These questions are central to understanding the effectiveness of the exchanges and also have broader implications for understanding selection markets where firm costs depend directly on which type of consumers purchase a product. We present a conceptual discussion of these issues and then investigate the burgeoning empirical evidence on these key questions.

In addition to studying the ACA regulations that are tailor-made to en- 
sure effective insurance market function, we discuss the potential benefits from facilitating competitive insurance markets (as opposed, e.g., to a single-payer system). These more traditional IO questions include, (i) how competitive have the ACA exchanges been? (ii) did competition lower prices? (iii) did competition improve variety? and (iv) did the competitive landscape lead to innovation in insurance or health care delivery? For the first three questions, we present some motivating empirical cases and cover the evidence available to date. For the latter question - one we argue is central to the rationale for relying on market-based provision of insurance - we discuss the limited research to date and highlight insurer product innovation as a key understudied area where there is significant room for new impactful research going forward.

The remainder of this article proceeds as follows. Section 2 discusses the IO underpinnings of ACA exchange market design. Section 3 discusses existing conceptual and empirical IO research on the ACA exchanges, with an emphasis on the specific regulations that relate to selection markets. Section 4 focuses on the classical IO questions of product entry and innovation with the goal of assessing the benefits from competitively provided insurance. Section 5 concludes with discussions of (i) how existing research informs ACA modifications going forward and (ii) how new research can fill in our knowledge gaps on the industrial organization of the ACA.

\section{Health Insurance Market Design and the ACA}

We begin by revisiting the features that make health care markets unique Arrow (1963)). Typical textbook product markets require little regulation to efficiently allocate products to consumers. Production costs and pricing strategies determine market supply and consumer willingness-to-pay determines demand. In a free market, supply and demand equilibrate and consumers who value products more than the cost of their production purchase them.

In contrast, there are at least three key ways that health insurance markets differ from typical product markets:

1. Consumer Right to Health Care and Affordability: in a typical product market, if consumers cannot afford to buy the product, then they are not able to access it. Health care is almost universally viewed as an intrinsic "right" for consumers to have access to. If consumers cannot afford the price of health care services, in many cases, society wants to 
find a way to fund those services. This motivates the existence, e.g., of Medicaid for low-income consumers, subsidies in the ACA health insurance exchanges, and policies that require hospitals to treat patients who show up at the emergency department, regardless of their ability to pay. Thus, while economists often neglect underlying moral arguments or imperatives, market regulation and market function are inextricably linked to the need to provide basic health care to all individuals in society.

2. Adverse Selection: In a typical product market, firm production costs are completely independent of the characteristics of consumers purchasing the product. This is not true in health insurance, where the health status of the person purchasing insurance directly determines insurer costs.

This issue manifests in a variety of ways in health insurance markets. First, consumers purchasing insurance may have asymmetric information and know more about their health risk than insurers (see e.g., Arrow (1963)). This can lead to market unravelling where high cost consumers purchase more generous insurance, driving up prices and in turn making the product attractive to only very high cost consumers. This further increases prices again, potentially leading to an unravelling in the market for generous insurance where healthier consumers who want greater risk protection cannot obtain it because they do not want to pay the cost to pool with sicker consumers (see, e.g., Akerlof 1970), Rothschild and Stiglitz (1976), Cutler and Reber (1998), Cutler and Zeckhauser (2000)).

Second, in health insurance markets affordability and the desire to remove long-run premium risk necessitates regulation prohibiting or severely limiting price discrimination. If affordability were not a concern, market regulators could potentially remove issues related to adverse selection by allowing price discrimination based on individual-level projected costs (see, e.g., Handel et al. (2015)). However, in practice, when health insurance contracts are one year in duration, as is typical, it is generally better for both efficiency and equity to limit price discrimination.

This, in turn, can generate adverse selection "on observables" where consumers do not have asymmetric information about their health status but they still generate adverse selection because insurers cannot tailor prices to health status (Finkelstein and Poterba (2008)). Even if the insurer and consumer both know that the consumer is likely to spend a lot, if price 
discrimination prohibits charging that person different prices, that person's plan choice can generate adverse selection and a negative externality on healthy consumers interested in purchasing more generous coverage. In practice, adverse selection based on "unpriced observables" is a much more pressing concern in health insurance markets than adverse selection based on asymmetric information ${ }^{1}$

As we will discuss in more depth below, in markets like the Affordable Care Act exchanges, adverse selection can be a pressing concern both on the intensive margin (selection of different plans within a market) and on the extensive margin (whether or not a consumer purchases in the market at all).

3. Moral Hazard: In a typical product market, how consumers use the product does not determine supplier costs. In health insurance, when consumers typically pay only a small portion of care costs, over-consumption or "moral hazard" is a significant concern. A large body of research shows that, when consumers face lower copayments for health care, they consume more health care (see, e.g., Newhouse (1993) and Brot-Goldberg et al. (2017)). This generates a tradeoff for insurance contract design between risk protection and moral hazard (Zeckhauser (1970)): more coverage means greater financial risk protection for consumers but also means greater moral hazard and more consumption of potentially unnecessary care 2

Given this trade-off, regulators and insurers have focused on the level of cost-sharing in insurance contracts, with a goal of limiting over-consumption and costs without severely eroding risk protection. In addition to navigating this trade-off with cost-sharing, insurers and regulators can work outside of this trade-off and ration care subject to a given level of costsharing. These non-price mechanisms include:

\footnotetext{
${ }^{1}$ Contrary to the theory of asymmetric information as implemented in many models, it is plausible that an insurer knows more about an individual's health status than they do, at least on many dimensions. Insurers have huge volumes of data on health and increasingly use this to understand risk.

${ }^{2}$ The welfare consequences of moral hazard are ambiguous since there is now a significant body of work showing evidence for "behavioral hazard" whereby consumers forego needed / valuable care when faced with higher costs on the margin (see, e.g., Baicker et al. (2015a)). Since the classic welfare trade-off between moral hazard and risk protection underlies much of the discussion related to contract design and the Affordable Care Act, throughout this article we primarily discuss the possibility of efficiency-reducing moral hazard, though these efficiency consequences could be mitigated or reversed depending on the extent of behavioral hazard.
} 
- Provider Networks: in the ACA exchanges, most insurers form provider networks that only pay for health care delivered at an innetwork provider, determined via ex ante insurer-provider contracting. This restricted access allows insurers to secure lower prices from providers and also to steer consumers towards more efficient providers generally (see, e.g., Ho (2009). Drug formulary design is an analogous restriction used by health plans in the prescription drug space.

- Gatekeeping: many insurers restrict access via gatekeeping that requires consumers to gain permission from the insurer to obtain specific kinds of care. This can manifest, e.g., by insurers requiring primary care provider authorization for specialty care, or, e.g., via prior authorization that requires insurer review of a patient's case before care is obtained (Dunn et al. (2021)).

- Queuing: some insurers also ration care via queuing or waitlists, a form or rationing that is often paired with gatekeeping and/or network restrictions. Systems with queuing deliver care at slower rates and often prioritize more vs. less necessary care when determining waiting times. Queuing also introduces hassle costs to consumers that may screen out less-needed care.

Overall, while insurers in the Affordable Care Act exchanges have limited flexibility to alter cost-sharing, they have significantly more flexibility to alter non-price rationing strategies such as network / formulary design, gatekeeping, prior authorization, and queuing. Consequently, these avenues are some of the primary potential avenues for private insurers to deliver value in a competitive landscape, something that we discuss in more depth below.

Clearly, health insurance markets face a number of impediments to function effectively. Key alternatives to market-based health insurance provision include single-payer systems where the government pays private providers to deliver care (e.g., Canada) or nationalized health systems where the government pays and provides for care (e.g., the UK). While it is not our purpose in this article to cover these alternative health system designs, it is instructive to briefly discuss the potential advantages of market-based provision in order to evaluate whether these advantages have materialized in the Affordable Care Act exchanges. 
Markets offer a number of potential key advantages in health insurance provision (Enthoven et al. (2001)). These include:

- Innovation: it is possible that many private insurers competing for market share will enact efficiency-enhancing interventions at a faster rate than government-funded care. The underlying premise draws from the classical argument that the incentive to profit and the ability to pursue different products will lead to the best products materializing and rising to the top. Then, in a competitive market, insurers will lower premiums to attract market share and pass through most of their cost-advantages to consumers.

In health insurance, there are myriad potential opportunities to innovate. Methods for rationing care are the most important area. Insurers in the ACA exchanges have meaningful flexibility to ration care in the different ways discussed above including, e.g., network design, formulary design, prior authorization restrictions, and gatekeeping. Insurers could also develop alternative organizational structures, such as vertical integration into so-called Integrated Delivery Networks (IDNs). In addition, insurers could innovate in terms of consumer non-health experience, through simple, clear and effective plan administration.

- Matching: having many private insurers offering coverage also allows for better potential matching of consumers to insurance products. Singlepayer health systems typically provide consumers with limited options while markets can let consumers choose between high-cost less restrictive and low-cost more restrictive options, according to their preferences. Since consumers can freely choose products and insurers can freely offer them, there are potentially meaningful efficiency gains to be had from effective matching of consumers to differentiated products.

An important potential impediment to realizing these value propositions is consumer choice frictions. Active and well-informed consumers are a key ingredient into effective market function. As we discuss in depth in the next section, there is now substantial evidence that consumers struggle to make choices in insurance markets. With this impediment in mind, we also discuss the empirical evidence on whether private insurance markets such as the ACA exchanges actually deliver significant value in terms of product innovation and matching. 


\subsection{ACA Exchange Regulations}

The ACA exchanges were set up as a market-based system with significant regulation designed to avoid the pitfalls of market-based insurance provision without removing its potential benefits (Kaiser Family Foundation (2011)). This "managed competition" model was proposed and advocated for by Enthoven et al. (2001) and underpins many important health care markets in addition to the ACA exchanges such as, e.g., Medicare Part D prescription drug insurance, privatized Medicare health coverage (Medicare Advantage) and nationally regulated exchanges in the Netherlands and Switzerland. The key regulations underpinning the ACA include:

- Consumer Subsidies: In order to make coverage accessible and affordable for all, the Affordable Care Act set up subsidies for individuals purchasing coverage with a sliding income-based scale. Subsidies are set so that the lowest income consumers in the market (starting at $138 \%$ of the Federal Poverty Line (FPL)) can obtain coverage at essentially no cost. As consumer income increases (up to $400 \%$ of the FPL) their subsidies decrease. The subsidies are given as a lump sum payment designed to make a certain class of care (Silver, $70 \%$ actuarial value) affordable (at most $8.5 \%$ of income). If consumers want to purchase additional coverage with more financial generosity or greater provider access, they are responsible for the full marginal contribution between their subsidy and the full plan premium.

In addition to premium subsidies, lower income consumers (those below $250 \%$ of the FPL) receive cost-sharing subsidies so that when they purchase a baseline Silver option they are responsible for a much lower portion of cost-sharing than what is quoted in the plan design.

- Limits on Price Discrimination and Guaranteed Issue: In order to ensure that coverage is affordable and accessible for sicker consumers, the ACA prohibits price discrimination, except in a few cases such as limited age-rating and extra charges for smokers (see Kaiser Family Foundation (2011)). This is paired with "guaranteed issue" regulation that requires insurers to allow anyone who wants to buy coverage at the quoted premium rate. Conditional on other market characteristics, these regulations help ensure affordable coverage for sick consumers and protect consumers from premium reclassification risk. However, limiting pricing on health status 
can lead to market-crippling adverse selection if not paired with other complementary regulations. Consequently, the ACA designers included myriad provisions to protect against adverse selection.

- Individual Mandate: To protect against extensive margin adverse selection (selection into or out of the market based on health status) the ACA contains an individual mandate that requires all individuals to hold minimum coverage. Individuals can have creditable coverage through any source including, e.g., employer markets, Medicare, Medicaid, an ACA exchange or a non-ACA individual marketplace. The mandate has been enforced as a tax penalty given to those who do not show evidence of minimum coverage. The mandate is important because it requires both healthy and sick people to have coverage at all times. Without it, the concern is that the market could become severely adversely selected, driving up premiums, limiting coverage options and, in the extreme, leading the exchanges to unravel entirely (see e.g., Cutler and Zeckhauser (2000)). In practice, the individual mandate was set to $\$ 0$ in 2017.

- Actuarial Design Regulation: the ACA sets up four permissible tiers of coverage levels that insurers can offer Platinum (90\% actuarial value), Gold $(80 \% \mathrm{AV})$, Silver (70\% AV) and Bronze (60\% AV). Actuarial value is the proportion of total health spending a plan covers for an average consumer in the market. There are several reasons to restrict the contract space insurers can offer. First, it makes it very hard for insurers to offer financial features with the goal of selecting primarily healthy consumers (Layton et al. (2015)). This is a significant aid in preventing adverse selection via contract design. Second, it makes consumer shopping experiences much simpler: they can choose a level of financial protection first and then choose which insurer they want without worrying that they are missing an opportunity on the financial dimension (see, e.g., Ericson and $\operatorname{Starc}(2016 \mathrm{a}))$. This, potentially, helps unlock value creation in the market by allowing shoppers to be more informed and more price sensitive to efficiency-enhancing innovation and/or matches.

- Risk-Adjustment Subsidies, Reinsurance and Risk Sharing: in addition to consumer incentives to select certain plan based on their health status, insurers have the incentive to "cream-skim," i.e., select healthy

consumers. While the contract design regulation mentioned above helps 
restrict insurers' ability to do this, they still have a lot of leeway in product design (which is potentially valuable) and they can still use these less regulated dimensions to attract certain types of consumers.

Risk-adjustment subsidies and reinsurance subsidies limit insurer profits from selecting consumers based on their health status. Risk-adjustment subsidies are transfers between insurers that send money from insurers enrolling healthier consumers on average to those enrolling sicker consumers on average. These transfers are arranged by the regulator and health status is typically assessed on an ex ante basis in order to limit the impact of insurer treatment effects on consumer risk scores. When implemented effectively, these transfers can greatly limit intensive margin (within market) adverse selection: insurers have dulled incentives to attract healthy consumers vs. sick consumers and insurers enrolling sicker consumers on average can pass through positive risk-adjustment transfers into lower premiums. In this case, risk-adjustment transfers sever the link between premiums and the average cost of enrollees, removing the key mechanism causing adverse selection in insurance markets. Reinsurance subsidies insure insurers against especially high ex post enrollee costs, limiting their concerns about selecting consumers with the potential for especially high ex post spending. Finally, risk sharing limited the potential losses facing insurers with the government covering a portion of losses beyond specific thresholds. Risk sharing is symmetric meaning profits are also limited for insurers.

These are the core regulations for understanding the industrial organization of the ACA exchanges 3 We now turn to a discussion of the empirical evidence on ACA exchange performance, drawing on the conceptual discussion in this section.

\footnotetext{
${ }^{3}$ There are many other important ACA regulations that impact exchange function including (i) the mandate for employers to offer coverage or pay a fine (employer mandate) (ii) whether a state regulator provides additional curation for plans allowed to enter the market (regulator curation) (iii) Medicaid expansion, which had an important impact on the types of consumers likely to select into the ACA exchanges and (iv) website regulation designed to make plan comparisons simple. We discuss these additional regulations further as needed in the next section, in the context of existing empirical research.
} 


\section{Empirical Evidence}

It is instructive to consider the evolution of ACA enrollment in the individual markets as a whole, before turning to particular regulations and market design questions. Enrollment increased initially, growing from 10.6 million insured through the individual market prior to the ACA in 2013 to 15.5 million in 2014 and a peak of 17.4 million in 2015 across both ACA- and non-ACAmarketplaces (Fehr et al. (2019)). Over the same period, premiums were also relatively low. From 2014-2016 premiums were lower than Congressional Budget Office forecasts (Adler and Ginsburg (2016), Layton et al. (2018)). The complexion changed appreciably beginning in 2017, following a concerted effort by the Republican Congress and the Trump Administration to remove key aspects of ACA regulations and broader uncertainty about a full repeal. (Fehr et al. (2019)) In 2017, 44 states saw a decline in enrollment, with the largest declines among those above $400 \%$ of FPL who did not receive subsidies. Enrollment in 2017 fell to 15.2 million and declined further, to 13.8 million in 2018, after which enrollment grew. Premiums on exchanges also grew significantly in 2017 but subsequently leveled off in 2019 and have fallen since. The ACA, and individual market coverage, has fluctuated since 2014 but, overall, coverage levels in the U.S. remain dramatically higher than they were in 2013. In $20199.2 \%$ of the US population was uninsured compared to $14.6 \%$ in 2013 prior to the introduction of the ACA-marketplaces and regulations.

\section{$3.1 \quad$ Subsidies}

A central pillar of the ACA is the provision of subsidies to make coverage affordable for all and to encourage enrollment more generally. As of 2015, among the uninsured approximately $22 \%$ (around 7 million people) qualified for some form of premium tax credit (Garfield and Cox (2021)). The decomposition of policy impacts on the ACA by Frean et al. (2017) finds that among those qualifying for subsidies, the entirety of increased coverage can be attributed to subsidies. This is approximately $40 \%$ of the entire coverage increase due to the ACA and the entire coverage increase coming from ACA exchange enrollment, underscoring the central role played by subsidies 4

The important role played by subsidies is demonstrated by Tebaldi (2017) using data on California's exchange and a rich model of insurance demand. He

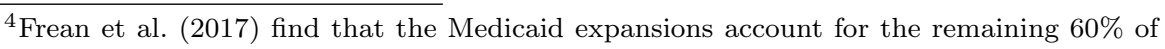
the coverage increase due to the ACA. 
shows that younger enrollees are both healthier and more price elastic. Therefore, by reducing prices through subsidies adverse selection is reduced, further lowering premiums (though savings largely accrue to the government because they are paying subsidies). However, because subsidies are linked to affordability criteria while premiums are age-rated, there is a countervailing effect noted by Graetz et al. (2018). As premiums increase, subsidies rise more for older enrollees potentially exacerbating adverse selection. In either case, these papers make clear that the existence of subsidies played a key role in enrollment, selection and prices under the ACA.

One of the biggest pieces of evidence for the importance of subsidies is the simple observation that by 2020 almost the universe of ACA exchange enrollment occurred amongst those with some subsidy. From 2017 to 2020 the share of exchange enrollees with a premium tax credit began at $84 \%$ and increased to $87 \%$, reflecting both the level and trend for the ACA exchanges to largely cater to subsidized coverage. There are a number of plausible causes for these patterns. Coverage through the non-ACA individual market may offer those not receiving subsidies access to plans they prefer, though concerns exist about the quality of those plans that are able to skirt product standardization and coverage minimums on ACA exchanges. For federal exchanges not supported by states it is also plausible that the outreach and marketing affected demand or, worse, exacerbated partisan views of insurance marketplaces. Bursztyn et al. (2021) demonstrate an important pattern of partisan selection out of ACA exchanges towards private non-group coverage. Not only do they find that the Republican's differentially substitute away from ACA coverage towards nonACA marketplaces, but also that this occurs primarily amongst healthier Republicans, leading to adverse selection on ACA exchanges that raises the price of coverage and, thereby, the amount paid for subsidies.

The structure of subsidy design also presents important trade-offs for policy makers. The premium tax credits adopted in the ACA are "price-linked subsidies." That is, they increase as the price of insurance rises. The use of price linked subsidies, as Jaffe and Shepard (2020) show, has the advantage that enrollees are protected from the uncertainty associated with the cost of insurance over time. However, this comes at a cost. By linking subsidies to price, price competition on the exchanges is softened. Using data from the Massachusetts insurance exchange Jaffe and Shepard (2020) estimate that the subsidies increased prices by $1-6 \%$ due to softening price competition and more so in less competitive markets. 
The tension present in subsidy design is one we find consistently in considering the IO of the ACA and its implementation. One needs to carefully evaluate what might be gained from competition (e.g., lower prices, innovative new products) and the degree to which policy decisions, particularly those that insulate consumers from costs, facilitate or mitigate competition.

In addition to the positive impacts of subsidies on coverage and adverse selection it is crucial to assess to normative impacts of subsidies, i.e., the overall social value they deliver via these mechanisms. Doing so raises a critical issue in assessing demand for insurance. In a standard market, we might simply assess underlying willingness-to-pay for coverage and compare that to the cost of subsidies. In fact, in a standard market without any market failures it must be the case that subsidies distort demand and lower welfare. Health insurance, however, differs substantially from standard markets.

As we have discussed, health insurance deviates for at least two important reasons. First, policy makers and society have a number of reasons to increase insurance coverage reflecting the externalities of uninsurance. These externalities include the fact that, as a society, we generally want to provide care when people are sick, regardless of insurance status. Thus, the cost of care for the uninsured is born primarily through uncompensated care and through other related mechanisms. In addition to this inefficient 'tax', which makes care for the insured more expensive and causes significant stress to the uninsured, there are additional reasons to be concerned about insurance coverage being unaffordable to low income populations. For example, insurance is a critical gateway to care in the United States, particularly for preventive care. As a result, expanding insurance coverage can reduce costs later and may also correct so called "internalities" in which consumers under-utilize valuable medical care (Baicker et al. (2015b), Brot-Goldberg et al. (2017)). Second, insurance markets are subject to widespread information frictions and poor consumer choices making the typical IO toolkit for welfare analysis that relies on revealed preference more challenging (see, e.g., Handel and Schwartzstein (2018)).

Tebaldi et al. (2019) develop a rich model of demand for ACA plans offered in California and use it to consider the role of subsidies in demand on coverage choices, consumer surplus, and government spending. They find that a $\$ 10$ decrease in monthly premium subsidies would cause between a 1.6-7\% decline in the proportion of low-income adults with coverage. Based on their demand estimates, this would generate a reduction in total annual consumer surplus between $\$ 63$ and $\$ 78$ million, while the savings in yearly subsidy outlays would 
be between $\$ 238$ and $\$ 604$. million. The demand estimates used for welfare depend on the assumption that plan choices reflect underlying utility.

The other important type of ACA subsidies is cost-sharing reduction (CSR) payments that were available to those with incomes between 100 and $250 \%$ of FPL. Before they were eliminated in 2017, CSRs made plans far more valuable for those who qualified. Lavetti et al. (2019) link all-payer claims data from Utah to income data that determine CSRs. The authors demonstrate that cost sharing subsidies were associated with higher spending for those who qualify. Shi (2016) also finds some evidence for income manipulation to qualify for CSRs. Despite these potential distortions, there are arguments for CSRs, particularly if policy makers and market designers believe that there are important liquidity constraints or internalities that may mitigate effective demand for care when facing high cost sharing. These effects have been shown to be important in high deductible health plans offered to employee populations and the same effects seem plausible in ACA exchanges (see Baicker et al. (2015b), Brot-Goldberg et al. (2017)). Despite the importance to policy and intrinsic interest to IO economists, there is little work assessing the degree to which CSRs, either as implemented or in some optimal form, improve plan design and welfare, for low-income enrollees by balancing moral hazard and risk protection.

When CSR payments were eliminated by the Trump Administration in 2017, insurers responded by "silver loading" in which they increased premiums on silver (70\% actuarial value) plans. Since those plans had more generous coverage and are used to set subsidies, this increased the cost of premium subsidies, even though CSR subsidies were reduced. Thus, it is not clear that reducing CSR payments lowered the cost of the ACA nor improved the efficiency of plan design. It does make clear that accounting for the strategic response of firms is critical to policy design.

\subsection{Individual Mandate}

Subsidies are a crucial tool for making coverage affordable. This in turn makes is possible to introduce an individual mandate to require that everyone hold coverage, with the explicit goal of eliminating extensive margin adverse selection. How well did the individual mandate accomplish this goal?

In practice evidence is mixed on the impact on mandate on enrollment. Survey based approaches projected the mandate would reduce uninsurance by 8-23\% (Fiedler (2017)). Microsimulation models using pre-ACA data projected 
much larger effects of the mandate ranging from 30 to $35 \%$. These projections proved to be substantially larger than the observed magnitude attributable to the mandate. Updated CBO microsimulation estimates using post-ACA data improved the predictive performance and project that the mandate reduced uninsurance by $21 \%$ (Office (2019)). Frean et al. (2017) find no effect of the mandate itself on enrollment, with the entirety of coverage expansion due to subsidies and Medicaid expansion. Aizawa and Fang (2020) also show that the individual mandate was not critical to coverage expansions using a model of the interactions between the labor market and the ACA. Additionally, survey studies of the mandate's impact show limited impacts of the mandate on enrollment. For example, only $19 \%$ of Californian's enrolled through the exchange say that the mandate/penalty influenced their decision to get coverage (Fung et al. (2019)).

We are also interested in the elasticity of enrollment with respect to the mandate penalty level. Lurie et al. (2021) use detailed administrative tax data to assess the impacts of the mandate penalty on demand. They find a relatively small impact of penalty level on coverage with every $\$ 1$ increase in monthly penalty increasing coverage by $.2-.3$ percentage points.

A subset of papers have, however, find an important role for the mandate penalty, particularly the existence of the penalty at the extensive margin. Saltzman (2019) explores detailed data for Washington and California and finds that the mandate had a large effect, though most of the effect is at the extensive margin. Jacobs (2018) studies the response to the mandate for those above $400 \%$ of the FPL who, therefore, did not qualify for any subsidized coverage. This population is of intrinsic interest and also allows further isolation of the mandate alone because premium subsidies are not relevant (though all of the other market reforms obviously apply). Using a variety of sources of variation and data from the ACS Jacobs (2018) estimate that mandate penalties account for a 7-12 percentage point coverage increase (of 13 percentage points in total).

Taken together, the evidence points towards a limited mandate impact, though there remains some disagreement that further research could help resolve. It is important to note that, to the extent that there is a gap between the earliest microsimulation estimates and the empirical findings quoted above, this likely demonstrates the important role played by perceptions of the mandate and general "taste for compliance" in practice (Frean et al. (2017), Saltzman (2019)). That is, requiring insurance was important for increasing enrollment, but the particular magnitude was less important in practice. 
Most of the work on the individual mandate's impact has focused on coverage. As discussed earlier the mandate was also specifically intended to play a critical role in market function by encouraging healthier/lower cost enrollees to join the market. Therefore, researchers have also studied the degree to which the mandate reduced adverse selection.

Hackmann et al. (2015) study this question in depth using data from the Massachusetts reform, a direct predecessor to the ACA exchanges. They find that, following the introduction of the individual mandate, coverage increased substantially and that the average cost of those covered fell, suggesting that the individual mandate was effective at reducing adverse selection in Massachusetts. Because Massachusetts had guaranteed issue and community rating prior to the introduction of the mandate, it is a useful setting to study the individual mandate against the regulatory backdrop introduced by the ACA. Using their model, Hackmann et al. (2015) compute the optimal individual mandate penalty given observed selection and find that it is close to the magnitude of the ACA penalty. It is worth noting, however, that this finding does not account for the later empirical results suggesting that the precise magnitude of the mandate penalty had less bearing on demand than a fully informed, rationale model would suggest.

\subsection{Contract Design Regulation}

Contract design regulations and limitations are a key policy variable in the ACA. In general, the ACA both increased standardization of plan designs and increased regulation of included plan benefits. As discussed earlier, product standardization has implications both for the ease of consumer choice in the market and for the ability to insurers to cream skim the best consumers through plan design.

There is now a meaningful body of work investigating the impacts of limiting the contract space on consumer choice ease. This work encapsulates a key tradeoff: one the one hand, limiting contract designs reduces the variety available to consumers and may also constrain tools insurers can use to innovate to lower prices, raise quality or both (Ericson and Sydnor (2017)). On the other hand, plan standardization can have important benefits in facilitating choice among plans. When plans are standardized shrouded attributes - aspects of plans that are hard for consumers to observe - play a smaller role in choice and, therefore, make choice easier for consumers and are less of a focus in product 
design by the supply side (Gabaix and Laibson (2006), Marzilli Ericson (2014), Ericson and Starc (2016b)). Plan standardization also serves to increase price competition, as has been shown in other markets relying on managed competition (Frank and Lamiraud (2009), Ericson and Sydnor (2017), Handel et al. $(2020))$. More generally, the value of offering additional choice in terms of vertical differentiation - varying levels of coverage generosity (e.g., Bronze, Silver, Gold and Platinum) - depends on the degree to which preferences for risk protection and the degree of potential moral hazard correlate with demand and costs (Marone and Sabety (2021)). Empirically, the value of offering substantial vertical choice has been found to be limited though the studies in this space typically study employer-insured populations, rather than ACA-insured populations (e.g., Marone and Sabety (2021), Ericson and Sydnor (2017), Ho and Lee (2021)).

Standardization and regulation of the ACA markets also served to shift the types of plans offered. The additional regulatory constraints - standardization and underwriting requirement - led to exit by more traditional insurers who focus on employer-sponsored markets. In contrast, Medicaid-focused plans (e.g., Centene) entered ACA marketplaces, at least in part due to their experience in working in regulated environments and managing narrow networks and managed care products (Miller and Moffitt (2018)). Thus, constraining offerings on the financial side and emphasizing other cost-reducing dimensions may have naturally favored certain kinds of insurers over others. For example, ACA plans have been characterized by the consistent use of narrow networks, likely in part due to the standardization on the financial aspect of coverage. In 2019 $72 \%$ of ACA plans had some form of narrow network, compared to $7 \%$ in the employer-sponsored market in 2018 (Carpenter and Chris (2018), Miller and Moffitt (2018)).

In addition, as the ACA was implemented there were increasing demands to allow certain types of plans that would not comply with minimum coverage requirements of the ACA to be "grandfathered" or "grandmothered" in. The extent of such plans varied across states depending both on regulation and coverage types before the ACA. Allowing grandfathered plans as well as alternative benefit designs that relax ACA exchange requirements trades-off the potential benefits of more choice with the potential costs of lower consumer protection, worse decision-making and cream skimming of healthy patients by insurers. For example, Sacks et al. (2020) demonstrate that allowing for more non-compliant coverage resulted in adverse selection into, and undermined, the 
ACA-compliant market. This suggests that for the managed competition format of the ACA exchanges to work well, preventing leakage to parallel products with lower requirements is crucial, especially in preventing extensive margin adverse selection.

\subsection{Risk Adjustment, Risk Corridors and Reinsurance}

One of the most important policy levers in ACA insurance markets - and more generally in managing insurance competition - is the use of tools to mitigate risk facing insurers by risk sharing. The need is somewhat counterintuitive if we think of insurers as firms who are supposed to be in the business of pooling and managing risk. In practice, however, these tools are critical to mitigating price swings, reducing welfare loss from adverse selection and facilitating entry and competition. Commonly referred to as "premium stabilization" tools in the ACA, they include risk adjustment, reinsurance and risk corridors. All were instituted at the inception of the ACA-marketplaces. The latter two components, however, were eliminated by the Trump Administration and Republican Legislative Branch in 2016.

Risk adjustment was included as a permanent component of the ACA. The approach relies on concurrent conditions to compute risk (i.e., expected cost). Plans then receive or provide transfers based on their enrollees relative to that market average such that are net zero. The ACA's reinsurance program provided payments to plans for particularly high cost enrollees. Plans received the incremental cost of an enrollee whose annual cost exceeds the so-called "attachment point," $\$ 45,000$ in 2014 and 2015 and $\$ 90,000$ in 2016 . In this way, reinsurance minimizes the incentives to avoid specifically high cost conditions and enrollees as well as limits the potential for premium growth or variation over time based on small numbers of very high cost individuals. The reinsurance program was funded through a pool into which insurers from both the individual and group insurance market contributed. Thus, the reinsurance program represents a net inflow of funds to the individual market, a subsidy (Layton et al. (2018)). The third leg of the "premium stabilization" stool was the risk corridor program. The risk corridor program effectively limited the potential losses a plan could make in a year as well as the possible profit. The ACA risk corridor program covered $50 \%$ of losses(profits) above $103 \%$ medical loss ratio (MLR) (below 97\%) and $80 \%$ beyond 108\% MLR (below 92\% MLR) (Sacks et al. (2021)).

Risk sharing design and implementation has received substantial attention 
from economists, due at least in part to the fact that it is a mainstay of numerous managed competition models of insurance markets (e.g., Medicare, the Netherlands). Risk sharing in general requires an important trade-off between greater risk sharing that reduces selection, lowers premiums and facilitates entry versus incentives to innovate in reducing enrollee costs - a critical form of innovation in insurance markets (Geruso and McGuire (2016), Layton et al. (2016)).

Risk sharing, in its different forms, also leads to strategic responses by the supply side of the market, a central consideration in designing market policies, and even in deciding to rely on market-based provision. Brown et al. (2014), Carey (2017) and Geruso and Layton (2020) provide evidence on how risk adjustment alters plan design and innovation as well as coding practices in Medicare, a setting with a mature and, arguably, successful risk adjustment programs.

In the ACA, Geruso et al. (2019b) find that the combined premium stabilization tools largely mitigated incentives to select against unhealthy enrollees. Despite the overall impact, though, they find distortions on the supply side targeting high cost enrollees where feasible, conditional on risk sharing. These individuals can be identified based on demand for specific drugs that make them consistently unprofitable leading to distortions in formulary design consistent with theories of adverse selection. The paper is particularly important in considering the ACA insofar as they are able to show the distortions due to adverse selection - both in supply and demand - but, more importantly, the limited degree to which it occurs given the "premium stabilization" tools in the ACA.

Sacks et al. (2021) study the risk corridor program specifically, exploiting the rapid removal of the program in 2016 empirically. Their model demonstrates the role played by risk corridors in determining pricing by insurers. When insurers are protected from losses they have greater incentive to bid lower. Sacks et al. (2021) show that, consistent with their model, premiums increased following the removal of risk corridors in 2016. They do, however, face the common challenge that policy evaluation of the ACA must be done against the backdrop of tremendous political uncertainty about the existence of the program and marketplaces and large concurrent policy shifts. Nevertheless, their paper makes an important point that risk sharing programs interact with competition and supply side decisions in critical ways in the ACA, and in managed competition in insurance markets more generally. 
An additional important source of adverse selection is the extensive margin decision to insure through an ACA exchange. As Geruso et al. (2019a) demonstrate, the extensive margin and the intensive margin selection across plan types of the kind targeted by premium stabilization tools are inextricably linked. Subsidies and the individual mandate were the primary tools focused on the extensive margin but the ACA did address this potential, at least partially, by making premium rating rules, minimum benefit standards and cost sharing rules cover both on-Marketplace and off-Marketplace plans. Furthermore, risk adjustment transfers were for all individual plans and premiums had to be the same on- and off-Marketplace. Insurers also had to offer off-Marketplace plans if they chose to participate in the ACA Marketplaces, though the reverse was not true. Whether, and how, off-exchange marketplaces functioned and interacted with ACA-marketplaces in practice is not well studied empirically. Given the important interaction, both through competition and as a result of regulation, this is a fruitful area of research.

\subsection{Exchange Structure and Market Design Lessons}

In theory, the delegation of market design to the states represents an opportunity to empirically evaluate and learn from the ACA due to the variation in state level market operations and decisions. Like many aspects of the ACA, however, the practical realities deviated. Many states did not develop their own exchanges and, instead, relied on federally operated Obamacare exchanges. As with almost every aspect of the ACA, policy decisions and market outcomes took place against a backdrop of significant political uncertainty at the Federal level making identification difficult. Despite this, we can make some general assessments about market design and exchange operations that seem to have been effective, and vice versa. We can also learn from states that did develop robust marketplaces (e.g., Covered California) (Enthoven and Baker (2018)).

A critical goal for marketplace designers is facilitating entry to support price competition. There is consistent evidence that price competition has been successful in ACA marketplaces, particularly as insurers compete to be the lowest or second lowest silver plan (Burke et al. (2014), Jacobs et al. (2015), Frank (2019)). For example, Jacobs et al. (2015) estimate that an additional entrant lowers average premiums by $1.2 \%$ and, perhaps more importantly, benchmark premiums by an average of $3.5 \%$. Parys (2018) finds that monopoly insurers increase silver premiums by an average of $50 \%$ in 2018 , primarily due to increased 
costs for the lowest cost plans offered.

An important design decision facing state exchanges was how to define the geographic rating areas in which insurers compete; essentially determining the market. Different states took very different approaches to this with important implications for entry, competition and price. States that defined markets (i.e., rating areas) based on population, usually by anchoring markets in an urban area and tying surrounding suburbs and rural areas, were far more successful in attracting entry and offering consistent choice of insurance options. Dickstein et al. (2015) estimate that this combination approach increased the number of insurers in a market by $27-37 \%$ and resulted in annual premium reductions of \$200-300 (3.3-5.4\% lower). Florida and Texas offer a notable contrast. Florida defined markets as counties, regardless of population, whereas Texas defined markets based on urban areas and included surrounding geographies. These decisions resulted in the 254 counties in Texas consolidating into only 26 markets while Florida allowed insurers to enter each of 67 different options at their discretion (Frank (2019)).

California also offers an instructive model for a successful exchange operation. Enthoven and Baker (2018) demonstrate key features that have made managed competition successful in California. Notably, Covered California the State's exchange - took on a role as an active purchaser, negotiating detailed plan designs and standardizing aspects of the benefit even within cost sharing tiers. Covered California also invested heavily in marketing outreach and focused on consumer enrollment tools to facilitate search and simple plan comparison. These efforts have resulted in a robust and relatively stable market with $95 \%$ of state residents offered two or more insurers and $80 \%$ with three or more (Enthoven and Baker (2018)).

Future work that focuses on how states developed exchanges as a whole, not just on one aspect of their policy decisions, would be valuable to policy makers as well as contributing to broader questions of market design that concern IO economists.

\subsection{Interaction with Other Markets: Medicaid Expansion and Employer-Sponsored Insurance}

While our primary focus is on the individual-market ACA exchanges, because these exchanges are typically the residual claimant for the uninsured, they have important interactions with other parallel insurance products. Two key inter- 
actions to consider are with (i) Medicaid coverage for low income populations and (ii) employer-sponsored markets, which insure the majority of Americans.

A central pillar of the ACA was the expansion of Medicaid to cover the universe of individuals under $138 \%$ of the FPL. If this had been implemented as initially envisioned, it would have dramatically increased coverage for low income populations nationwide. In reality, the 2012 Supreme Court decision that allowed states to opt out of Medicaid expansion led to a division where blue states expanded Medicaid as intended and many red states did not. To date, 39 States have expanded Medicaid, 14 of which only did so after 2014. Given the magnitude of fiscal support for Medicaid the lack of expansion represents a remarkable role for political economy in determining outcomes and reflects the partisan divide around the ACA.

While the ACA Medicaid expansion was a core part of the ACA, its implications for the IO of the ACA exchanges is mostly limited to its impact on individual participation in the exchanges. In states where Medicaid was expanded, generally, fewer lower income people entered the exchanges, with implications for the market shares and costs of exchange insurers. Notably, recent work by Holmes (2021) finds that the Medicaid expansions under the ACA dramatically lowered prices on ACA individual insurance exchanges by reducing the risk of those enrolling on the exchanges. In states that did not expand, those under $138 \%$ of FPL had the option to enroll through ACA exchanges. Because those who were sickest were more likely to enroll, not expanding Medicaid served to raise the average price of on exchange insurance, even for enrollees far above the income threshold for Medicaid. The effects are large. Holmes (2021) estimates that expanding Medicaid under the ACA lowered average premiums by approximately $9 \%$. This cross-market selection thus has a meaningful impact on extensive margin adverse selection and underscores the important interactions between firms operating in the ACA and regulation of parallel insurance markets.

In addition to Medicaid, the ACA exchanges have potentially important interactions with employer-sponsored coverage. The ACA designers understood that generous ACA exchange subsidies and robust markets could lead to employers dropping coverage, moving employees towards the exchanges and subsidies, and reducing their costs in the process. Consequently, the ACA included an employer mandate designed to ensure that employers either maintained coverage or pay a large fee per employee substituting to an ACA exchange. In practice, however, the implementation of the employer mandate was repeatedly delayed, 
first from 2014 to 2015, and then from 2015 to 2016, when it was introduced with much less bite than originally intended.

Despite the potential dangers from a weak employer mandate, the broad patterns of insurance coverage follow the ACA suggest employer-sponsored coverage was largely unaffected (Abraham et al. (2016). A number of studies find a significant increases in employer-sponsored coverage following the Massachusetts Reform (Lyons (2017), Long et al. (2012), Kolstad and Kowalski (2016)) as well as a decline in ESHI when the employer mandate was removed to comply with the ACA rules in 2014 (Sommers et al. (2018)).

Such "crowd-in" runs counter to the concerns expressed by policy makers as well as the predictions based on existing models of the interaction of the labor market with insurance markets. Kolstad and Kowalski (2016) develop a simple model demonstrating that crowd-in occurs when an individual mandate makes demand for insurance as a part of the benefit package greater. Insofar as an employer has a comparative advantage in offering benefits directly they may prefer to offer ESHI rather than pay the incremental wages to purchase insurance on the individual market. Kolstad and Kowalski (2016) estimate that in Massachusetts, after including the individual mandate penalty the average worker valued almost the entire compensating reduction in wages for jobs offering ESHI.

These results have also largely been born out, at least in aggregate, with the ACA. Early microsimulation models predicted significant reductions in ESHI given the weakened employer mandate. In practice, there has been little reduction in ESHI and, if anything, an increase in coverage through employers, even with delayed and small penalties for employers for not offering insurance. There are several possible hypotheses for why reductions in ESHI did not occur including, notably, (i) the tax advantage for ESHI premiums relative to individual market premiums (ii) individuals viewing exchange plans as a poor substitute for ESHI (ii) higher exchange plan costs due to limited insurer participation. As noted earlier, the exchange plans have primarily catered to the lower income populations receiving federal subsidies, potentially leading to higher premiums than would occur for an individual market with consumers without subsidies who are likely to be more price sensitive.

Overall, because the ACA exchanges comprise a relatively small portion of the insured population and are the residual claimant of parallel markets, crossmarket interactions are important for studying the IO of these exchanges. While current evidence suggestions meaningful interactions in practice with Medicaid 
and less meaningful interactions with ESHI, more evidence is needed to assess the implications of these cross-market interactions, both as they have occurred thus far and how they might occur in different potential environments going forward.

\subsection{Behavioral Economics of Demand and Market Design}

The architects of the managed competition paradigm typically envision consumers acting as rational agents, selecting the best coverage for themselves and, in the process, disciplining the market, leading to lower premiums and insurer innovation. In practice, there is now ample evidence that consumers have a hard time effectively selecting among health plans, often leaving significant sums of money and significant consumer surplus on the table (see, e.g., Domurat et al. (2021), Handel and Kolstad (2015b), Handel and Schwartzstein (2018), Spinnewijn (2017), Handel (2013), Chandra et al. (2019)).

One example of an important documented decision making heuristic in health insurance markets is the propensity of consumers to focus on premiums as opposed to other plan costs when making choices. Such behavior has been documented in many settings (see, e.g., Abaluck and Gruber (2011) in Medicare Part D, Gruber et al. (2020) in Medicare Advantage) including, importantly for the ACA, choices on individual insurance exchanges (see, e.g., Ericson and Starc $(2012))$. One consequence of consumer premium minimization is enrollment by individuals in plans with lower premiums and higher cost-sharing (e.g., Bronze plans). This gives insurers the incentive to compete on premiums but not as much on product design otherwise, removing some of the intended benefits of competition. Additionally, the focus on premiums may lead to poorer matches of consumers with products, limiting a benefit of having a market with variety as opposed to a single-payer market. Research has shown that decisions in general, and with respect to this specific bias, can be improved in a number of ways including plan standardization (Ericson and Starc $(2016 \mathrm{~b})$ ) and decision aids (e.g., Politi et al. (2016), Gruber et al. (2020)).

In addition to within-market choice frictions, consumer choice difficulties are also present on the extensive margin when enrollees, particularly those who have access to subsidies, do not enroll through ACA exchanges. Broadly, marketing efforts have been shown to be essential in increasing enrollment. Domurat et al. (2021) present compelling experimental evidence on the role for informational interventions in overcoming frictions to enrollment on California's ex- 
change. They also demonstrate an important relationship between underlying health/cost and frictions. Those newly enrolled by the intervention were on average $37 \%$ less expensive. This study shows that reducing consumer choice frictions on the extensive margin may be especially important to facilitating effective ACA exchange function, both by lowering average costs and premiums and by increasing market share, allowing insurer fixed costs to be spread out over a larger patient base.

In addition to the classical IO avenues through which choice frictions impact market function, there is also an important potential interaction between choice frictions and adverse selection. The Domurat et al. (2021) study shows this on the extensive margin for the ACA exchanges while there is a now a significant body of research in health insurance generally showing the potential for complex interactions between choice frictions and risk selection. For example, as discussed in depth in Handel et al. (2019) and Handel (2013), if consumers choice frictions lead to lessened connection between risk and coverage generosity, choice frictions can actually mitigate adverse selection and improve market function. Handel et al. (2019) characterize the market foundations that determine whether policies to improve consumer choices increase or decrease adverse selection. The paper demonstrates that as heterogeneity in consumer surplus increases relative to heterogeneity in costs, improving choices at the individual level is more likely to be beneficial in aggregate as well, once the downstream effects of selection on premiums are accounted for. The paper also highlights the complementarity between friction reducing policies and the effectiveness of risk-adjustment policies. One consequence is that the relative success of riskadjustment policies in the ACA exchanges makes policies to improve consumer choices more effective and less likely to negatively impact markets through increased adverse selection.

It is important to note that, in addition to the economic implications of choice frictions, the presence of choice frictions can potentially bias measurement of consumer surplus if a neoclassical revealed preference approach is used. Handel and Kolstad (2015b) and Handel and Schwartzstein (2018) discuss this potential bias and note ways that researchers can overcome these biases through alternative empirical welfare criteria. 


\section{Entry and Innovation in Insurance Markets}

Section 3 focused on how specific ACA regulations, especially those set up to deal with issues of affordability and adverse selection, impact the IO of the ACA exchanges. We now turn to a discussion of whether the ACA exchanges deliver on the potential benefits of competitive insurance markets, such as product variety and innovation, in practice.

While the potential for competition to induce product entry and innovation is clear conceptually, there is a relative paucity of research actually measuring product variety and insurer innovation. A likely reason is that innovation can be subtle and multi-faceted, making it hard to measure in practice, especially without clear characterizations of how insurers can innovate.

In general, by innovation, we refer to changes to insurance product design that lower cost and/or raise quality in a way that moves at least some individuals towards an ideal cost-quality frontier. The ACA exchanges were specifically set up to encourage innovation on the non-financial aspects of coverage, e.g., network design, formulary design, prior authorization, gatekeeping, and other dimensions discussed in Section 2. If insurers innovate in this manner then, depending on the extent of consumer choice frictions, consumers will gravitate towards more attractive plans, hopefully leading to a more efficient health care system than what could be achieved with a more centralized single-payer system 5 .

A key question is, therefore, whether ACA created conditions in which welfare enhancing innovations by insurers were rewarded. Despite that, there is relatively little evidence. Handel et al. (2021). They study the employer-sponsored insurance market using all-payer claims data from Utah. Using situations in which entire employers switch from one plan to another they are able to decompose the contributors to health care utilization, including total cost as well as specific high and low value types of care. They find a limited role for specific insurance brands in differences in care delivery and cost. E.g., moving from AETNA to Select Health Care (an affiliate of Intermountain) has only small impacts on the care received or cost overall. To the extent that there are differences, they decompose those differences into the impacts of bargaining, network

\footnotetext{
${ }^{5}$ While innovation is a key potential benefit of delivering health insurance through private markets, there is meaningful evidence that, in the U.S., Medicare is another critical source of innovation. Though beyond the scope of this paper, evidence suggests that Medicare has played a more important role in pricing innovation than private plans, at least for the private employer-sponsored market (Clemens and Gottlieb (2017)
} 
design, consumer steering within network, and other factors that impact prices and quantities. They argue that one impediment to innovation is that there is little demand response to high value offerings. Employers do not seem to adopt plans that offer their employees better options.

Another paper that makes progress on this topic outside of the ACA exchanges is Abaluck et al. (2020), which studies differences in mortality effects for Medicare Advantage plans. They use a design that leverages plan exits from the market to show meaningful heterogeneity in plan mortality effects across plans. They show that consumers place little weight on these differential mortality effects in plan choices, potentially because these effects are not generally known to consumers. They show that moving beneficiaries away from the bottom $5 \%$ of plans by mortality effects could save tens of thousands of elderly lives every year.

Perhaps most relevant for the ACA exchanges, Geruso et al. (2020) show that, holding cost-sharing equal, when beneficiaries are randomly assigned to plans that the plans can impact overall spending by up to $30 \%$ relative to one another. They show that the effects come through quantities rather than price differences and that consumers lower quantities across the board, including likely wasteful and likely valuable care. Since, as we discuss below, Medicaid managed care plans have some similarities with ACA exchange plans, this study provides some insight into the potential range of cost differences induced by non-price insurer strategies. While the papers described here start to characterize how insurers differ from one another in terms of product offerings, they are not really able to assess the welfare implications of different plan designs. In a typical product market, consumer choices would reveal those implications, but due to choice frictions in insurance markets it is unlikely to be the case in the ACA exchange context. In this vein, both the Abaluck et al. (2020) study and the Geruso et al. (2020) study show meaningful insurer differentiation in terms of effects on quantities but find limited consumer response to that differentiation.

\subsection{Entry and Exit by Different Types of Insurer}

As the discussion above shows, rigorous research on value creation in private insurance markets is limited, despite the importance of measuring this for assessing the success of the ACA exchanges and other managed competition markets. Future work that unpacks the different potential domains for insurer innovation and investigates the micro-foundations for why consumers seem not to respond 
to these differences will be quite valuable. The papers discussed in the prior section are relevant for measuring private insurer differentiation but do so in markets that are not the ACA exchanges. In this section, we present some simple cases from the ACA exchanges that are suggestive of competition generating entry and innovation by insurers. We note, however, that these examples are, just that, examples, but hopefully will help motivate research on these questions going forward.

Prior to the ACA, individual insurance markets were highly concentrated. In 2011, the average HHI was 4,200 (Dafny et al. (2015)). At inception, ACA Marketplaces were also relatively concentrated, more so than the outside individual insurance market (Layton et al. (2018)). In 2014, roughly a third of marketplaces had one or two insurers and the average marketplace offered products from approximately 4 insurers (Dafny et al. (2015)). Subsequent entry, however, led many exchanges to offer a variety of products, by insurer brand, as well as offer competitive exchanges. In 2016 the average state exchange offered 6 different insurers' products (McDermot et al. (2016)). As with many of the policy tools in the ACA, competition declined from there through 2017 and 2018. At the low point in 2018, the average state only offered 3.6 insurers. Entry then returned, from 2018 on, leading to a relatively broad set of offerings as of 2021 with the average exchange offering 5 insurers' products, $46 \%$ of states offering more than 3 insurers and less than $10 \%$ with a monopolist (McDermot et al. (2016) ). Given these broad patterns, what do we know about the underlying differences in the plans that entered (and exited) the ACA exchanges over time?

There is limited evidence on this topic but there is some evidence on use of narrow networks, an important potential area for insurer innovation. Narrow networks have the potential to facilitate a number of valuable new models for insurers including the ability to negotiate lower prices, more effectively managed care and improve quality by selecting higher quality providers and more easily steering patients to those providers (Ghili (2016), Ho and Lee (2019)). Dafny et al. (2017) studies narrow networks in ACA exchange plans and finds that narrow networks for ACA plans have been shown to lower cost by an estimated $16 \%$ and have served to hold down benchmark premiums for Silver plans, lowering the cost of federal subsidies by approximately $10.8 \%$. Lower cost, however, is not sufficient to demonstrate welfare gains. Lower cost could come from reductions in quality or steering patients away from high value care (see e.g., Cutler et al. (2000) for a discussion of prices and quantities in generating welfare gains 
in insurance and Brot-Goldberg et al. (2017) for a discussion of demand for high and low value care in response to insurer plan designs). Wallace (2019) study the function of narrow networks using random assignment to Medicaid managed care plans, a setting relatively similar to ACA-marketplaces. He finds that narrow networks reduce cost but due so in relatively blunt ways, largely by creating hassle costs that lower quantities of both high and low value care in equal measure without lowering prices substantially. He then considers an alternative assignment mechanism that can improve welfare, underscoring the linkage between exchange design, consumer choice and the gains from insurer innovation. The research to date makes clear the need for more work determine whether insurer innovation on this dimension has actually generated value in ACA marketplaces, as opposed to reducing access to care for consumers with high choice frictions.

Risk adjustment, reinsurance payments and risk sharing also played an important role in facilitating entry and determining the types of plans that entered. These policy/market design tools limit the need for an insurer entering an ACA exchange to manage large swings in risk due to small numbers of high cost enrollees as well as effort required to design benefits to mitigate adverse selection. However, risk corridors and MLR restrictions can also have the effect of limiting upside in high profit years, an effect which disproportionately impacts smaller carriers that may smooth over years rather than across a large book of business. Abraham et al. (2014) show that in the first year of exchange operation (2014) these factors seemed to matter. Less than $10 \%$ of incumbent insurers offered products on an ACA exchange and those that did were disproportionately larger and had experience operating in the individual market in that state.

One additional interesting trend in entry following the ACA was the introduction of plans by insurers who had previously only served the Medicaid population (e.g., Centene). These entrants had relatively distinct operating models with a greater focus on care management and networks that were better set to serve lower income populations. Furthermore, churn between Medicaid offerings and marketplace plan following changes in income meant that a Medicaid operator may be better positioned to internalize switching and minimize switching costs to enrollees. The patterns of growth for traditional Medicaid plans are interesting: in 2016 Medicaid insurer enrollment had approximately $15 \%$ market share. By 2017 that had grown to 26 percent and held at 27 percent in 2018. This growth was concurrent with the decline in enrollment in national and regional insurer plans not active in the Medicaid market. Their market 
share fell from roughly a third of the market in 2016 to $14 \%$ in 2018, suggesting a pattern of substitution from traditional national insurers (including United who exited the market in 2017) to Medicaid managed care plans (Holahan et al. (2020b), Holahan et al. (2020a)). This suggests that the non-price rationing tools typically used by privatized Medicaid insurers naturally lent themselves to the ACA exchanges, though whether these product differences lead to efficient care is an open question (Wallace (2019)).

It is also important to note that insurers also had to learn to adapt to the ACA environment and that firm learning likely played an important role in product offerings over the first several years of the exchanges. While evidence on this point is limited, recent work by Lucarelli and Saltzman (2021) suggests that insurer pricing strategy improved over time in California from 2014 through 2016. While their study focuses on pricing, it is likely that similar learning occurred on other product dimensions as well.

\section{Going Forward: IO and the ACA}

The ACA exchanges have now been enrolling consumers for over 7 years. We have learned a lot about the industrial organization of these markets, especially in regard to how the key regulations underlying the managed competition paradigm impact insurance market outcomes. There is a significant body of research studying the impacts of subsidies, the individual mandate, contract design regulation, and the three Rs implemented to directly counteract adverse selection (risk-adjustment, reinsurance, risk corridors). We also have some evidence on the importance of cross-market interactions, e.g., how Medicaid expansion and employer-market policies impact the exchanges.

In addition, we have ample evidence that consumers generally have difficulty making choices in the exchanges (and in insurance markets in general). This calls into question the assumption that competition will generate value by having consumers select the most innovative and efficient plans, directly leading to success for those plans. While researchers have begun to investigate whether and how private insurers innovate, we are still at the beginning of understanding if and how insurers create value. Much of the related existing research occurs in non-ACA managed competition markets (e.g., Medicaid managed care, Medicare Advantage, Medicare Part D) and even this research only looks at small slices of the value creation problem. 
Given this, we feel that new research on the value generated by competition via private insurers will be especially useful. There are a number of directions to proceed. First, it is important to leverage tools from other research on product innovation and productivity that may not be central to the IO literature. The organizational economics literature may provide insights into how organizations like insurers can/do innovate, allowing us to measure innovation from a different perspective (see, e.g., Cutler (2011) and Bloom and Van Reenen (2007)). Additionally, the productivity literature, which spans multiple traditional fields in economics, may help to more precisely determine the factors of production for private insurance plans and, in turn, tell us how these factors vary across insurers over time (see, e.g., De Loecker and Syverson (2021) for a recent survey).

Related to this is the issue of whether modifications to the traditional managed competition setup can help deliver additional value. In the ACA exchanges, some states operate in this traditional setup, allowing free insurer entry and having consumers be the main disciplining force. Alternatively, many states have used a curated exchange setup where a state agency determines whether or not each plan meets sufficient quality criteria before allowing them to enter the market. The regulator acts as an intermediary for consumers and plans, often bargaining down premiums with insurers and ensuring adequate network quality before allowing an insurer to participate in the exchange. To date, there is limited rigorous research that we are aware of that studies the impact of this kind of market curation on market outcomes and, especially, on value creation by private insurers (e.g., Enthoven and Baker (2018) point to the important role of these tools in California). If the state regulator, acting as an intermediary, can help step in for consumers with choice frictions, this is another avenue to discipline the market and, potentially, lead to value creation via private insurers 6

Overall, the ACA exchanges have been successful in navigating the difficulties inherent to health insurance markets. Plans are affordable to consumers and adverse selection has been limited due to the subsidies, mandate, contract regulation, and risk-adjustment policies. We hope that the next decade of IO research on the exchanges will help us understand whether this great effort to set up a well-functioning market is worth the difficulty of doing so, relative

\footnotetext{
${ }^{6}$ An alternative approach, which hasn't been implemented in practice, is to set up more aggressive consumer steering by regulators, via tools like smart defaults (e.g., Handel and Kolstad (2015a)).
} 
to different common models of public or quasi-public insurance provision, and point to ways to further improve markets to foster welfare enhancing innovation.

\section{References}

Abaluck, Jason and Jonathan Gruber, "Choice Inconsistencies Among the Elderly: Evidence from Plan Choice in the Medicare Part D Program," American Economic Review, 2011, 101 (4), 1180-1210.

_ , Mauricio Caceres Bravo, Peter Hull, and Amanda Starc, "Mortality Effects and Choice Across Private Health Insurance Plans," NBER Working Paper 27578, 2020.

Abraham, Jean, Anne B Royalty, and Coleman Drake, "Employersponsored insurance offers: largely stable in 2014 following ACA implementation," Health Affairs, 2016, 35 (11), 2133-2137.

Abraham, Jean M, Roger Feldman, and Kosali Simon, "Did they come to the dance? Insurer participation in exchanges," American Journal of Managed Care, 2014, 20 (12), 1022-30.

Adler, Loren and Paul B Ginsburg, "Obamacare premiums are lower than you think," Health Affairs Blog, 2016, 21.

Aizawa, Naoki and Hanming Fang, "Equilibrium labor market search and health insurance reform," Journal of Political Economy, 2020, 128 (11), 42584336 .

Akerlof, George, "The Market for 'Lemons': Quality Uncertainty and the Market Mechanism," The Quarterly Journal of Economics, 1970, 84 (3), 488500 .

Arrow, Kenneth J, "Uncertainty and the welfare economics of medical care," American Economic Review, 1963, 53 (5), 941-973.

Baicker, Katherine, Sendhil Mullainathan, and Joshua Schwartzstein, "Behavioral Hazard in Health Insurance," The Quarterly Journal of Economics, 2015, 130 (4), 1623-1667.

_ , _ , and _ , "Behavioral hazard in health insurance," The Quarterly Journal of Economics, 2015, 130 (4), 1623-1667. 
Bloom, Nicholas and John Van Reenen, "Measuring and Explaining Management Practices Across Firms and Countries*," The Quarterly Journal of Economics, 11 2007, 122 (4), 1351-1408.

Brot-Goldberg, Zarek C, Amitabh Chandra, Benjamin R Handel, and Jonathan T Kolstad, "What Does a Deductible Do? The Impact of CostSharing on Health Care Prices, Quantities, and Spending Dynamics," The Quarterly Journal of Economics, 2017, 132 (3), 1261-1318.

Brown, Jason, Mark Duggan, Ilyana Kuziemko, and William Woolston, "How does risk selection respond to risk adjustment? New evidence from the Medicare Advantage Program," American Economic Review, 2014, 104 (10), 3335-64.

Burke, Amy, Arpit Misra, and Steven Howard Sheingold, Premium affordability, competition, and choice in the health insurance marketplace, 2014, Department of Health and Human Services, Office of the Assistant Secretary ..., 2014.

Bursztyn, Leonardo, Jonathan Kolstad, Aakaash Rao, Pietro Tebaldi, and Noam Yuchtman, "Adversarial Selection: Partisanship, Enrollment, and Costs in the Affordable Care Act Marketplaces," mimeo, 2021.

Carey, Colleen, "Technological change and risk adjustment: Benefit design incentives in Medicare Part D," American Economic Journal: Economic Policy, 2017, 9 (1), 38-73.

Carpenter, Elizabeth and Sloan Chris, "Health Plans with More Restrictive Provider Networks Continue to Dominate the Exchange Market," Washington, DC: Avelere.[Google Scholar], 2018.

Chandra, Amitabh, Benjamin Handel, and Josh Schwartzstein, "Behavioral Economics and Health-care Markets," Hadbook of Behavioral Economics - Applications and Foundations Vol. 2, 2019, pp. 459-502.

Clemens, Jeffrey and Joshua D Gottlieb, "In the shadow of a giant: Medicare's influence on private physician payments," Journal of Political Economy, 2017, 125 (1), 1-39.

Cutler, David and Sarah Reber, "Paying for Health Insurance: The TradeOff Between Competition and Adverse Selection," The Quarterly Journal of Economics, 1998, 113 (2), 433-466. 
Cutler, David M., "Where Are the Health Care Entrepreneurs? The Failure of Organizational Innovation in Health Care," Innovation Policy and the Economy, 2011, 11, 1-28.

Cutler, David M and Richard J Zeckhauser, "The anatomy of health insurance," Handbook of health economics, 2000, 1, 563-643.

_, Mark McClellan, and Joseph P Newhouse, "How does managed care do it?," The Rand journal of economics, 2000, pp. 526-548.

Dafny, Leemore, Jonathan Gruber, and Christopher Ody, "More insurers lower premiums: Evidence from initial pricing in the health insurance marketplaces," American Journal of Health Economics, 2015, 1 (1), 53-81.

Dafny, Leemore S, Igal Hendel, Victoria Marone, and Christopher Ody, "Narrow networks on the health insurance marketplaces: prevalence, pricing, and the cost of network breadth," Health Affairs, 2017, 36 (9), 16061614 .

Dickstein, Michael J, Mark Duggan, Joe Orsini, and Pietro Tebaldi, "The impact of market size and composition on health insurance premiums: Evidence from the first year of the affordable care act," American Economic Review, 2015, 105 (5), 120-25.

Domurat, Richard, Isaac Menashe, and Wesley Yin, "The role of behavioral frictions in health insurance marketplace enrollment and risk: Evidence from a field experiment," American Economic Review, 2021, 111 (5), 1549-74.

Dunn, Abe, Joshua D Gottlieb, Adam Shapiro, Daniel J Sonnenstuhl, and Pietro Tebaldi, "A Denial a Day Keeps the Doctor Away," Working Paper 29010, National Bureau of Economic Research July 2021.

Enthoven, Alain, Alan Garber, and Sara Singer, "Near-Universal Coverage Through Health Plan Competition: An Insurance Exchange Approach," Covering America: Real Remedies for the Uninsured, Editors J. Meyer and E. Wicks, 2001, Washington DC, 155-172.

Enthoven, Alain C, "The history and principles of managed competition," Health affairs, 1993, 12 (suppl 1), 24-48.

- and Laurence C Baker, "With Roots In California, Managed Competition Still Aims To Reform Health Care," Health Affairs, 2018, 37 (9), 1425-1430. 
Ericson, Keith and Amanda Starc, "How Product Standardization Affects Choice: Evidence from the Massachusetts Health Insurance Exchange," Journal of Health Economics, 2016, 50, 71-85.

Ericson, Keith M Marzilli, "Consumer inertia and firm pricing in the Medicare Part D prescription drug insurance exchange," American Economic Journal: Economic Policy, 2014, 6 (1), 38-64.

Ericson, Keith M Marzilli and Amanda Starc, "Designing and regulating health insurance exchanges: lessons from Massachusetts," INQUIRY: The Journal of Health Care Organization, Provision, and Financing, 2012, 49 (4), 327-338.

_ and _, "How product standardization affects choice: Evidence from the Massachusetts Health Insurance Exchange," Journal of Health Economics, 2016, 50, 71-85.

Ericson, Keith Marzilli and Justin Sydnor, "The questionable value of having a choice of levels of health insurance coverage," Journal of Economic Perspectives, 2017, 31 (4), 51-72.

Fehr, Rachel, Cynthia Cox, and Larry Levitt, "Data Note: Changes in Enrollment in the Individual Health Insurance Market through Early 2019," Data Note, Kaiser Family Foundation, 2019.

Fiedler, Matthew, "Taking Stock of Insurer Financial Performance in the Individual Health Insurance Market Through 2017," The Brookings Institution. https://www. brookings. edu/research/taking-stock-of-insurer-financialperformance-in-theindividual-health-insurance-market-through-2017, 2017.

Finkelstein, Amy and James Poterba, "Adverse Selection in Insurance Markets: Policyholder Evidence from the U.K. Annuity Market," Journal of Political Economy, 2008, 112, 183-208.

Frank, Richard G, "Making Choice and Competition Work in Individual Insurance in Health Reform Proposals," Commonwealth Fund Issue Brief, January, 2019, 30.

- and Karine Lamiraud, "Choice, price competition and complexity in markets for health insurance," Journal of Economic Behavior 83 Organization, 2009, 71 (2), 550-562. 
Frean, Molly, Jonathan Gruber, and Benjamin D Sommers, "Premium subsidies, the mandate, and Medicaid expansion: Coverage effects of the Affordable Care Act," Journal of Health Economics, 2017, 53, 72-86.

Fung, Vicki, Catherine Y Liang, Julie Shi, Veri Seo, Lindsay Overhage, William H Dow, Alan M Zaslavsky, Bruce Fireman, Stephen F Derose, Michael E Chernew et al., "Potential effects of eliminating the individual mandate penalty in California," Health Affairs, 2019, 38 (1), 147-154.

Gabaix, Xavier and David Laibson, "Shrouded attributes, consumer myopia, and information suppression in competitive markets," The Quarterly Journal of Economics, 2006, 121 (2), 505-540.

Garfield, Rachel and Cynthia Cox, "Estimates of Eligibility for ACA Coverage among the Uninsured in 2016," Data Note, Kaiser Family Foundation, 2021.

Geruso, Michael and Thomas G McGuire, "Tradeoffs in the design of health plan payment systems: Fit, power and balance," Journal of health economics, 2016, 47, 1-19.

- and Timothy Layton, "Upcoding: evidence from Medicare on squishy risk adjustment," Journal of Political Economy, 2020, 128 (3), 984-1026.

_, Tim Layton, and Jacob Wallace, "Are All Managed Care Plans Created Equal? Evidence from Random Plan Assignment in New York Medicaid Managed Care," NBER Working Paper 27762, 2020.

_, Timothy J Layton, Grace McCormack, and Mark Shepard, "The two margin problem in insurance markets," Technical Report, National Bureau of Economic Research 2019.

_, Timothy Layton, and Daniel Prinz, "Screening in contract design: Evidence from the ACA health insurance exchanges," American Economic Journal: Economic Policy, 2019, 11 (2), 64-107.

Ghili, Soheil, "Network formation and bargaining in vertical markets: The case of narrow networks in health insurance," Available at SSRN 2857305, 2016. 
Graetz, Ilana, Caitlin N McKillop, Cameron M Kaplan, and Teresa M Waters, "Lessons learned from the Affordable Care Act: the premium subsidy design may promote adverse selection," Medical Care Research and Review, 2018, 75 (6), 762-772.

Gruber, Jonathan, Benjamin R Handel, Samuel H Kina, and Jonathan T Kolstad, "Managing intelligence: Skilled experts and AI in markets for complex products," Technical Report, National Bureau of Economic Research 2020.

Hackmann, Martin B, Jonathan T Kolstad, and Amanda E Kowalski, "Adverse selection and an individual mandate: When theory meets practice," American Economic Review, 2015, 105 (3), 1030-66.

Handel, Ben and Jonathan Kolstad, Getting the Most from Marketplaces: Smart Policies on Health Insurance Choices, Brookings Institution Washington, DC, 2015.

_, Igal Hendel, and Michael D Whinston, "Equilibria in Health Exchanges: Adverse Selection Versus Reclassification Risk," Econometrica, 2015, 83 (4), 1261-1313.

Handel, Benjamin, "Adverse Selection and Inertia in Health Insurance Markets: When Nudging Hurts," American Economic Review, 2013, 103 (7), $2643-2682$.

- and Joshua Schwartzstein, "Frictions or mental gaps: what's behind the information we (don't) use and when do we care?," Journal of Economic Perspectives, 2018, 32 (1), 155-78.

_ , Jonathan Holmes, Jonathan Kolstad, and Kurt Levetti, "What Do Insurers Do Differently Than One Another? Managed Competition and Value Added," Technical Report, mimeo 2021.

Handel, Benjamin R and Jonathan T Kolstad, "Health insurance for" humans": Information frictions, plan choice, and consumer welfare," American Economic Review, 2015, 105 (8), 2449-2500.

_, _, and Johannes Spinnewijn, "Information frictions and adverse selection: Policy interventions in health insurance markets," Review of Economics and Statistics, 2019, 101 (2), 326-340. 
_, , , Thomas Minten, and Johannes Spinnewijn, "The social determinants of choice quality: evidence from health insurance in the Netherlands," Technical Report, National Bureau of Economic Research 2020.

Ho, Kate and Robin Lee, "Contracting over Rebates: Formulary Design and Pharmaceutical Spending," working paper, 2021.

- and Robin S Lee, "Equilibrium provider networks: Bargaining and exclusion in health care markets," American Economic Review, 2019, 109 (2), $473-522$.

Ho, Katherine, "Insurer-Provider Networks in the Medical Care Market," The American Economic Review, 2009, 99 (1), 393-430.

Holahan, John, Caroline Elmendorf, and Erik Wengle, "Which Types of Insurance Are Marketplace Enrollees Choosing?," Robert Wood Johnson Foundation, 2020.

_, Erik Wengle, and Caroline Elmendorf, "Marketplace premiums and insurer participation: 2017-2020," Washington, DC: Urban Institute, 2020.

Holmes, Jonathan, "Does Medicaid Make Private Health Insurance Cheaper?," Technical Report, mimeo, UC Berkeley 2021.

Jacobs, Paul D, "Mandating health insurance coverage for high-income individuals," National Tax Journal, 2018, 71 (4), 807-828.

_, Jessica S Banthin, and Samuel Trachtman, "Insurer competition in federally run marketplaces is associated with lower premiums," Health Affairs, 2015, 34 (12), 2027-2035.

Jaffe, Sonia and Mark Shepard, "Price-linked subsidies and imperfect competition in health insurance," American Economic Journal: Economic Policy, 2020, 12 (3), 279-311.

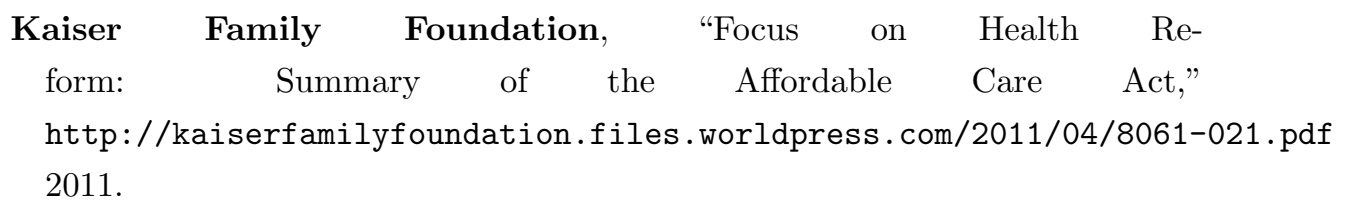

Kolstad, Jonathan T and Amanda E Kowalski, "Mandate-based health reform and the labor market: Evidence from the Massachusetts reform," Journal of health economics, 2016, 47, 81-106. 
Lavetti, Kurt J, Thomas DeLeire, and Nicolas R Ziebarth, "How do low-income enrollees in the Affordable Care Act Marketplaces respond to costsharing?," Technical Report, National Bureau of Economic Research 2019.

Layton, Timothy J, Ellen Montz, and Mark Shepard, "Health Plan Payment in US Marketplaces: regulated competition with a weak mandate," in "Risk Adjustment, Risk Sharing and Premium Regulation in Health Insurance Markets," Elsevier, 2018, pp. 491-522.

_ , Randall P Ellis, and Thomas G McGuire, "Assessing incentives for adverse selection in health plan payment systems," Technical Report, National Bureau of Economic Research 2015.

_, Thomas G McGuire, and Anna D Sinaiko, "Risk corridors and reinsurance in health insurance marketplaces: insurance for insurers," American journal of health economics, 2016, 2 (1), 66-95.

Loecker, Jan De and Chad Syverson, "Productivity and Industrial Organization," 2021. IO Handbook.

Long, Sharon K, Karen Stockley, and Kate Willrich Nordahl, "Coverage, access, and affordability under health reform: learning from the Massachusetts model," INQUIRY: The Journal of Health Care Organization, Provision, and Financing, 2012, 49 (4), 303-316.

Lucarelli, Claudio and Evan Saltzman, "Firm Learning in a Selection Market: The Case of the ACA Exchanges," Wharton working paper, 2021.

Lurie, Ithai Z, Daniel W Sacks, and Bradley Heim, "Does the individual mandate affect insurance coverage? Evidence from tax returns," American Economic Journal: Economic Policy, 2021, 13 (2), 378-407.

Lyons, Sean, "Are Employer Mandates to Offer Health Insurance Effective in Reducing Subsidized Coverage Crowd-Out of Employer-Sponsored Insurance?," American Journal of Health Economics, 2017, 3 (3), 370-391.

Marone, Victoria R and Adrienne Sabety, "Should There be Vertical Choice in Health Insurance Markets?," Technical Report, National Bureau of Economic Research 2021. 
McDermot, David, Anthony Damico, Cynthia Cox, Gary Claxton, and Larry Levitt, "Insurer Participation on the ACA Marketplaces, 20142021," Data Note, Kaiser Family Foundation, 2016.

Miller, Brian and Robert Moffitt, "Choice, Competition, And Flexibility, Part I: Post-ACA Consumer Challenges," Health Affairs Blog, 2018.

Newhouse, Joseph P., Free for All? Lessons From the RAND Health Insurance Experiment, Harvard University Press, 1993.

Office, Congressional Budget, "Federal subsidies for health insurance coverage for people under age 65: 2019 to 2029," 2019.

Parys, Jessica Van, "ACA marketplace premiums grew more rapidly in areas with monopoly insurers than in areas with more competition," Health Affairs, 2018, 37 (8), 1243-1251.

Politi, Mary C, Marie D Kuzemchak, Jingxia Liu, Abigail R Barker, Ellen Peters, Peter A Ubel, Kimberly A Kaphingst, Timothy McBride, Matthew W Kreuter, Enbal Shacham et al., "Show Me My Health Plans: using a decision aid to improve decisions in the federal health insurance marketplace," MDM policy \& practice, 2016, 1 (1), 2381468316679998 .

Rothschild, Michael and Joseph Stiglitz, "Equilibrium in Competitive Insurance Markets: An Essay on the Economics of Imperfect Information," The Quarterly Journal of Economics, 1976, 90 (4), 630-649.

Sacks, Daniel W, Coleman Drake, Jean M Abraham, and Kosali Simon, "Same Game, Different Names: Cream-Skimming in the Post-ACA Individual Health Insurance Market," INQUIRY: The Journal of Health Care Organization, Provision, and Financing, 2020, 57, 0046958020933765.

_, Khoa Vu, Tsan-Yao Huang, and Pinar Karaca-Mandic, "How do insurance firms respond to financial risk sharing regulations? Evidence from the Affordable Care Act," Health Economics, 2021, 30 (6), 1443-1460.

Saltzman, Evan, "Demand for health insurance: Evidence from the California and Washington ACA exchanges," Journal of Health Economics, 2019, 63, $197-222$. 
Shi, Julie, "Income Responses to Health Insurance Subsidies: Evidence from Massachusetts," American Journal of Health Economics, 2016, 2 (1), 96-124.

Sommers, Benjamin D, Mark Shepard, and Katherine Hempstead, "Why did employer coverage fall in Massachusetts after the ACA? Potential consequences of a changing employer mandate," Health Affairs, 2018, 37 (7), $1144-1152$.

Spinnewijn, Johannes, "Heterogeneity, Demand for Insurance and Adverse Selection," American Economic Journal: Economic Policy, 2017, 9 (1), 308343.

Tebaldi, Pietro, "Estimating equilibrium in health insurance exchanges: Price competition and subsidy design under the aca," Becker Friedman Institute for Research in Economics Working paper, 2017, (2017-05).

_, Alexander Torgovitsky, and Hanbin Yang, "Nonparametric estimates of demand in the california health insurance exchange," Technical Report, National Bureau of Economic Research 2019.

Wallace, Jacob, "What does a Provider Network Do? Evidence from Random Assignment in Medicaid Managed Care," Yale University Working Paper, 2019.

Zeckhauser, Richard, "Medical insurance: A case study of the tradeoff between risk spreading and appropriate incentives," Journal of Economic Theory, 1970, 2 (1), 10-26. 